\title{
Near-Threshold Fatigue Crack Propagation in an ECAP-Processed Ultrafine-Grained Aluminium Alloy
}

\author{
K. Hockauf ${ }^{a}$, T. Halle, M. Hockauf, M. F.-X. Wagner and T. Lampke \\ Chemnitz University of Technology, Institute of Materials Science and Engineering, Erfenschlager \\ Str. 73, 09125 Chemnitz, Germany \\ akristin.hockauf@mb.tu-chemnitz.de
}

Keywords: Fatigue crack propagation (FCP), load ratio sensitivity, equal-channel angular pressing (ECAP), ultrafine-grained aluminium alloy, two-parametric concept

\begin{abstract}
In the present work, the near-threshold fatigue crack propagation (FCP) at different load ratios is studied for an aluminium alloy processed by equal-channel angular pressing (ECAP). The conditions under investigation represent different stages of microstructural refinement as well as a ductility-optimized condition with superior crack growth properties, obtained by a combination of ECAP and aging. The results show a strong dependency of the threshold and its load ratio sensitivity on the grain size and grain size distribution. These observations can be rationalized on the basis of crack path tortuosity and the contribution of (roughness-induced) crack closure. Moreover, the experimental data is evaluated using the two-parametric concept of Vasudevan and Sadananda, which employs two necessary minimum conditions for crack growth, namely a critical cyclic $\Delta \mathrm{K}_{\text {th }}^{*}$, and a critical maximum stress intensity $\mathrm{K}^{*}$ max. The application of this concept shows a strong interaction of both parameters for all ECAP-processed conditions, where the ductility-optimized condition reveals superior FCP properties compared to the "as-processed" conditions.
\end{abstract}

\section{Introduction}

Fatigue crack propagation (FCP) in ultrafine-grained (UFG) materials produced by severe plastic deformation (SPD) has drawn increasing interest of international research [1, 2]. A main focus lies on the correlation of the fatigue threshold with microstructural features and mechanical properties such as grain dimensions, yield stress, susceptibility of cyclic hardening, slip character and others. These data are required in order to formulate microstructurally based explanations for the detrimental effect of grain refinement on the FCP performance. Establishing such correlations will support the elaboration of strategies to improve the overall fatigue and FCP behaviour, for example by a post-processing heat treatment or a combination of ECAP and aging [3-5].

A comprehensive approach includes the influence of load ratio $R=K_{\min } / K_{\max }$ on the fatigue threshold $\Delta \mathrm{K}_{\mathrm{th}}$. Several studies have shown that a decrease in grain size gradually decreases the load ratio sensitivity of $\Delta \mathrm{K}_{\mathrm{th}}[6,7]$. This is typically explained by the diminished effect of roughness induced crack closure. Independent from the research on UFG materials, a two-parametric concept was introduced in 1993 by Vasudevan and Sadananda [8]. This concept represents an alternate model to describe the load-ratio dependency of the fatigue threshold. Based on two necessary minimum conditions for crack growth, $\Delta \mathrm{K}^{*}{ }_{\text {th }}$ and $\mathrm{K}^{*}{ }_{\max }$, which are considered as intrinsic material properties and are themselves a function of microstructure, environment, etc., this theory intentionally omits an explanation based on the extrinsic factor of crack closure. The rationale for this approach was given by experimental observations referred to in $[8,9]$ which stated that the magnitude of closure contributions was not sufficient enough to account for the observed reduction of $\Delta \mathrm{K}_{\text {th }}$ with $\mathrm{R}$, in other words: an explanation merely based on closure would overestimate its actual contribution. Consequently, Vasudevan and Sadananda introduced a critical cyclic stress intensity $\Delta \mathrm{K}^{*}$ th (which represents the cyclic load amplitude to establish a characteristic cyclic damage) and a critical maximum stress intensity $\mathrm{K}^{*}{ }_{\max }$ (which represents the peak load to break open the bonds in a cyclically damaged region) to describe the preconditions for crack growth. Both parameters have to be 
met simultaneously to initiate crack propagation. In further studies, they defined classifications applicable for metals as well as alloys, ceramics and composites and - for the case of metals and alloys - evaluated the role of microstructural features and environment and their specific impact on $\Delta \mathrm{K}^{*}{ }_{\text {th }}$ and $\mathrm{K}^{*}{ }_{\max }[9]$. Thus, they provided a basis for continuative studies by other authors, who applied this model for the interpretation of their results on a high-strength aluminium alloy [10] and UFG low-carbon steel [11].

The work which will be presented here comprises a continuation of a previous study, published in [5]. The experimental basis was broadened for two additional load ratios in order to evaluate the impact of load ratio dependent effects for the different ECAP-processed microstructures with varying grain sizes and grain size distributions. After fitting the data using a linear approach [12], the two-parametric concept of $\Delta \mathrm{K}^{*}{ }_{\text {th }}$ and $\mathrm{K}^{*}{ }_{\text {max }}$ is applied.

\section{Experimental Details}

A commercially extruded aluminium alloy AA6060 was ECAP-processed at room temperature in a $90^{\circ}$ die with a cross-section of $15 \times 15 \mathrm{~mm}^{2}$. Repetitive pressings were conducted for two and eight passes following Route $\mathrm{E}$ [13], which consists of the following rotation pattern: $180^{\circ}, 90^{\circ}, 180^{\circ}, 90^{\circ}$ and so on. These conditions, referred to as "E2" and E8", were processed starting from the peak aged T6 condition "CG T6". For obtaining the optimized condition "E1opt", the material was solution-annealed at $525^{\circ} \mathrm{C}$, quenched and ECAP-processed for one pass. Subsequently, a short-time aging to peak strength $\left(170^{\circ} \mathrm{C}\right.$ for $\left.18 \mathrm{~min}\right)$ was performed.

The FCP behaviour was measured using single-edge bend specimens according to ASTM 399 [14] with a thickness of $6.5 \mathrm{~mm}$. They were extracted from the processed billets in "L-T" orientation (see Fig. 1 in [5]), to prevent the crack from deviating into the ECAP shear planes. The experiments were conducted in a RUMUL resonant testing machine for load ratios of $\mathrm{R}=0.1,0.4$ and 0.7 . The crack length was measured continuously using the RUMUL Krak Gages and Fractomat system, which utilizes the indirect potential method. After precracking for $1 \mathrm{~mm}$ at a constant $\Delta \mathrm{K}$ of $\sim 4 \mathrm{MPa} \mathrm{m}{ }^{1 / 2}$, $\Delta \mathrm{K}$ was lowered in small steps until $\Delta \mathrm{K}_{\mathrm{th}}$ was reached.

Grain sizes were evaluated from low-voltage scanning transmission electron micrographs (STEM), measuring about 120 to 150 grains from three to five micrographs for each condition. For each grain, the aspect ratio $(a r)$ as well as the grain size $(d)$ were calculated as $a r=(a / b)$ and $d=(a+b) / 2$, with $a$ being the semi-major and $b$ the semi-minor axis of the grain.

\section{Results and Discussion}

Microstructural characteristics and their evolution during ECAP and the "ductility-optimizing" heat treatment have been discussed thoroughly in [15] and [16]. In this section, a brief overview on grain size, the average values and its ranges, as determined from STEM is presented, Fig. 1 and 2. 


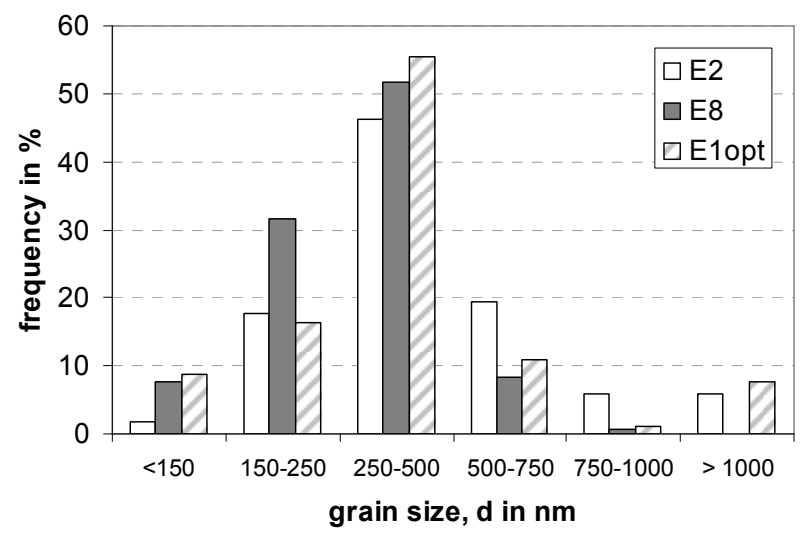

Fig. 1: Grain size distributions for the ECAP-processed microstructures. E2 and E1opt exhibit a remaining fraction of larger grains $(>1000 \mathrm{~nm})$, whereas E8 is completely refined.

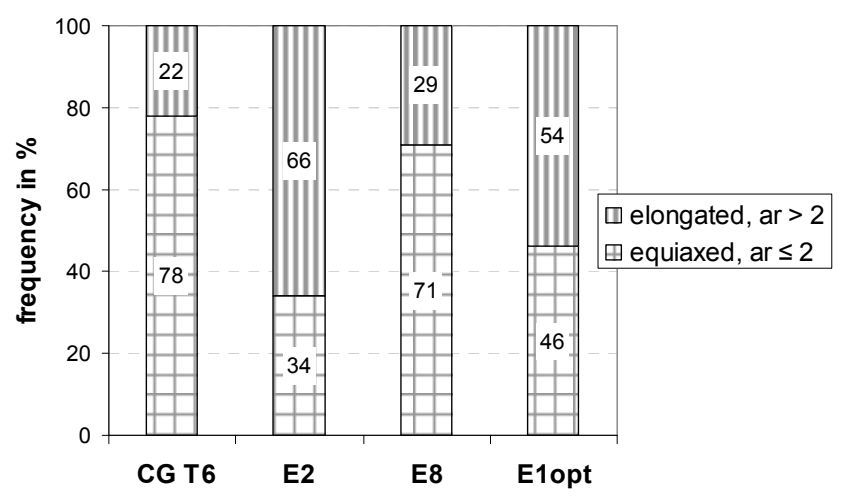

Fig. 2: Grain shape of all conditions under investigation. CG T6 as well as E8 mainly consist of equiaxed grains, whereas E2 and E1opt exhibit a significantly higher fraction of elongated grains.

Both the E2 as well as the E1opt condition exhibit a bimodal characteristic: as the deformation occurs along the same ECAP shear plane during the first and second pass, these microstructures consist to a major part of elongated grains that are stretched in the direction of macroscopic shear and typically more than $1 \mu \mathrm{m}$ in length. Besides that, "truly ultrafine" regions are formed, with equiaxed grains in the size of typically 150 to $500 \mathrm{~nm}$. During repetitive ECAP processing, the material gets worked along different shear planes, which results in a homogeneously ultrafine-grained structure for the E8 condition. In this state, the microstructure consists to a major part $(71 \%)$ of equiaxed grains with sizes ranging from 150 to $500 \mathrm{~nm}$. The initial condition CG T6 (CG = conventionally grained $)$ is not included in Fig. 2. Its microstructure consists of mostly equiaxed grains with an average grain size of $120 \mu \mathrm{m}$, with $85 \%$ of the grains in the range between 50 and $125 \mu \mathrm{m}$.

Near-threshold fatigue crack propagation at load ratios ranging from $\mathrm{R}=0.1$ to $\mathrm{R}=0.7$ is shown in Fig. 3 in detail for each condition. Fig. 4 depicts the values for the fatigue threshold $\Delta K_{t h}$ in dependence on the load ratio $R$. In this graph, a linear fit according to Barsom [12] is applied, which gives a good approximation and enables to inter- and extrapolate $\Delta \mathrm{K}_{\text {th }}$ for load ratios which have not been experimentally measured. 

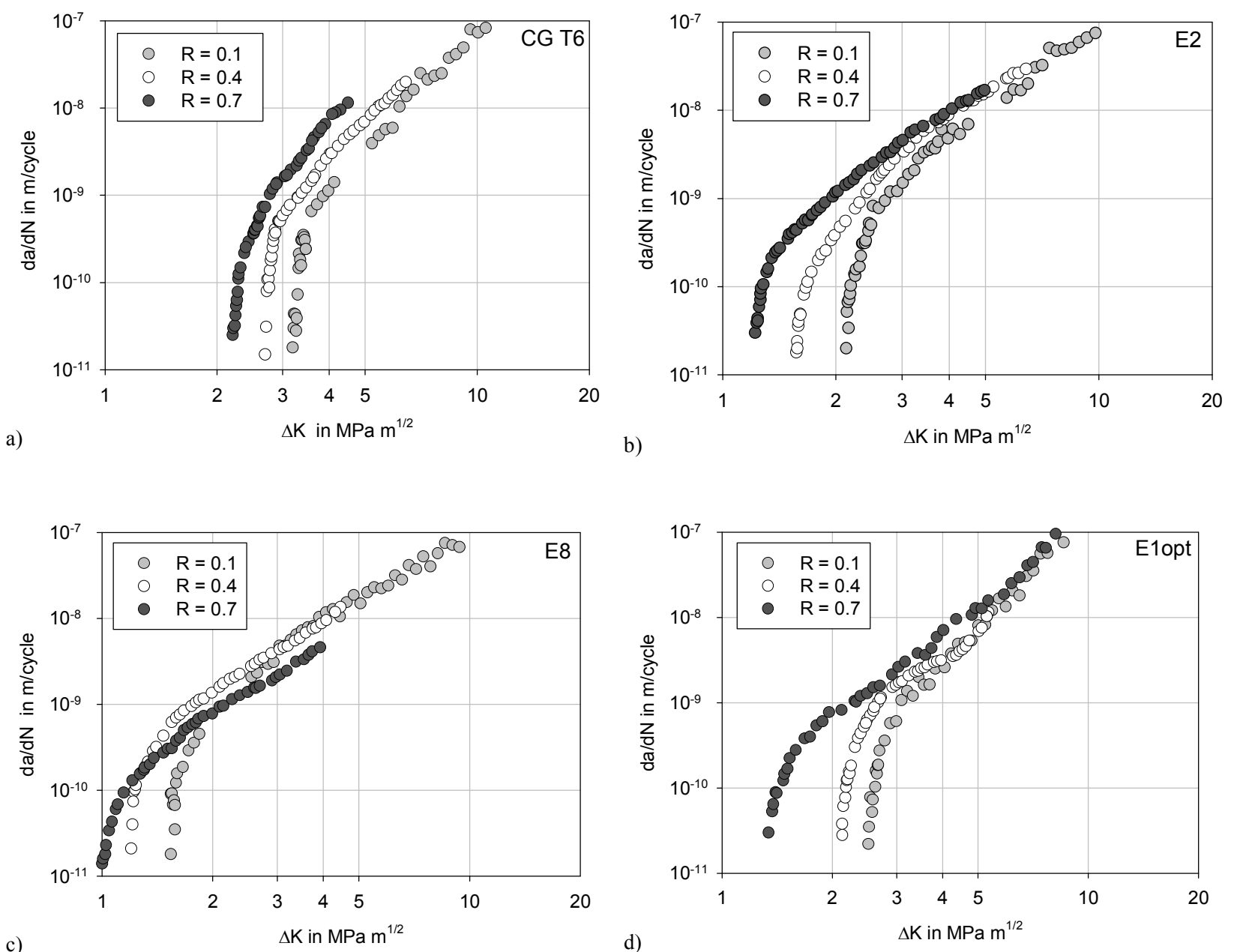

Fig.3:Fatigue crack propagation at load ratios from 0.1 to 0.7 for a) initial CG T6 condition, b) E2, c) E8 and d) E1opt.

All conditions exhibit a decrease in $\Delta K_{\text {th }}$ with increasing load ratio $R$. For all load ratios, the initial condition CG T6 reveals the highest threshold, followed by the two bimodal conditions E1opt and E2. The lowest $\Delta \mathrm{K}_{\mathrm{th}}$ is reached by the homogeneously UFG condition E8. In the near-threshold region, where crack propagation is strongly affected by the microstructure, grain size and, correspondingly, crack surface roughness are considered to be governing factors for both $\Delta \mathrm{K}_{\text {th }}$ as well as for its dependence on R. Crack deviation at grain boundaries effectively reduces the crack driving force, which leads to higher $\Delta \mathrm{K}_{\text {th }}$ for conditions with a larger grain size. Additionally, in the case of low load ratios and a rough crack surface, premature crack closure in the unloading cycle can lower the effective $\Delta \mathrm{K}$. In contrast to crack deviation, which is constant for all $\mathrm{R}$, the effect of roughness induced crack closure is only dominant at sufficiently low load ratios (where in the unloading cycle the opposite crack faces approach close enough to allow contact of the crack asperities).

For the case of precipitation-hardening aluminium alloys, the size and coherency of strengthening precipitates also plays an important role: small and coherent precipitates are known to have a beneficial effect on the threshold value [17]. This effect is less dominant than the effect of grain size (cf. [18]). But for comparison of E1opt and E2, which have similar grain sizes, it may serve as an explanation for the superior behaviour of the optimized condition. We note that this interpretation implies that E1 opt comprises very fine, coherent precipitates - smaller than in E2. This has not been experimentally investigated for these particular conditions yet, but studies of Roven et al. [19] and Cai et al. [20] report the presence of extraordinarily fine, coherent precipitates in Al-Mg-Si alloys which have been aged to peak strength after SPD. It is therefore quite likely that a similar effect occurs in the optimized condition considered here. 
The application of the two-parametric concept for the fatigue threshold is shown in Fig. 5. The displayed points of $\Delta \mathrm{K}_{\text {th }}$ have been derived from the linear fits shown in Fig. $4 . \mathrm{K}_{\text {max,th }}$ is calculated from $\Delta \mathrm{K}_{\mathrm{th}}$ as $K_{\text {max }, t h}=\Delta K_{t h} /(1-R)$.

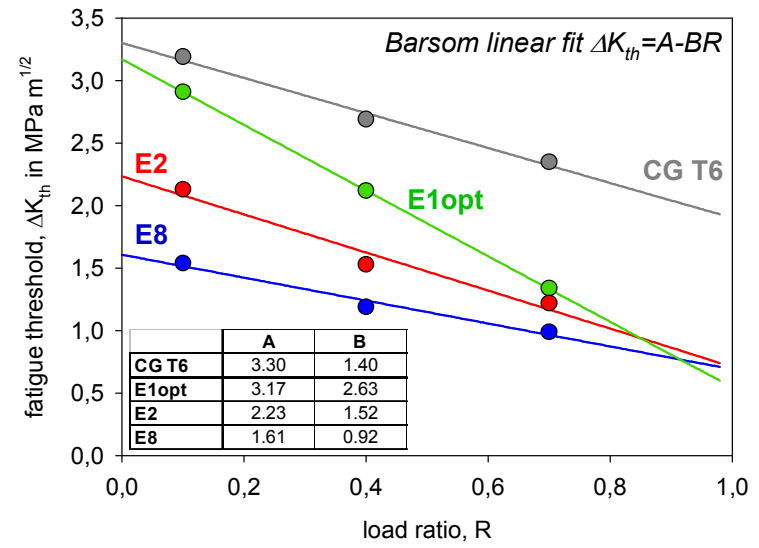

Fig. 4: Fatigue threshold $\Delta \mathrm{K}_{\mathrm{th}}$ from experiments (dots) and Barsom linear fit (lines), showing dependence of $\Delta \mathrm{K}_{\text {th }}$ on load ratio $\mathrm{R}$.

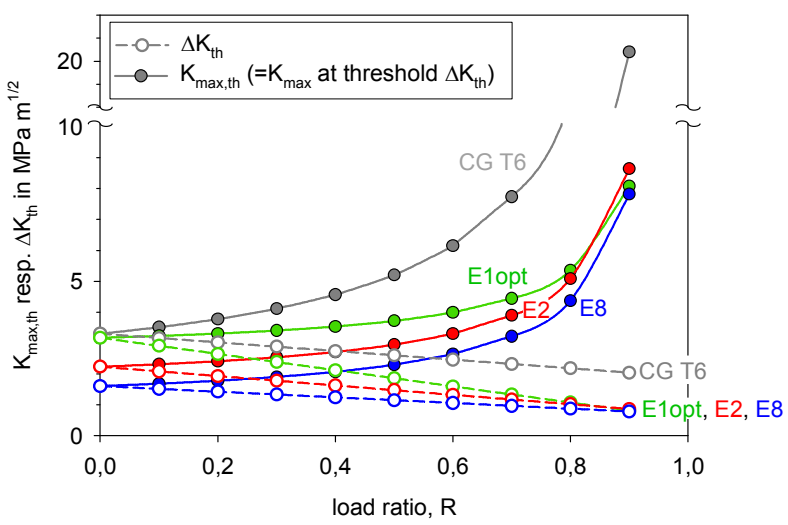

Fig. 5: Evolution of $\Delta \mathrm{K}_{\text {th }}$ and corresponding maximum applied stress intensity factor $\mathrm{K}_{\max \text {,th }}$ - the two necessary minimum conditions for crack propagation.

In order to enable crack growth, both of the necessary minimum conditions have to be fulfilled. The governing influence is therefore exerted by the lower of both parameters. For instance, if $\Delta \mathrm{K}_{\mathrm{th}}$ is significantly lower than $K_{\text {max,th }}$, crack growth occurs $\Delta K$-controlled, since $K_{\max }$ has to be raised in order to achieve the necessary $\Delta \mathrm{K}$. For low load ratios in Fig. $5, \Delta \mathrm{K}_{\text {th }}$ and $\mathrm{K}_{\text {max,th }}$ are within the same order of magnitude, which means that both parameters interact, with none of them exerting the "major controlling" influence. With increasing $\mathrm{R}, \mathrm{K}_{\max \text {,th }}$ increases exponentially, making $\Delta \mathrm{K}$ the controlling factor at higher load ratios. For the CG T6 condition, this change is observed at lower load ratios than for the UFG conditions (E1opt, E2 and E8). Similar results have been obtained by Chapetti et al. [11] for UFG low-carbon steel. Referring to [9], they identify pronounced crack tip blunting as the mechanism of major influence in the region of interaction. This means that crack tip blunting will influence the near-threshold FCP in the UFG materials more effectively - and up to higher load ratios - than in the material with larger grain size.

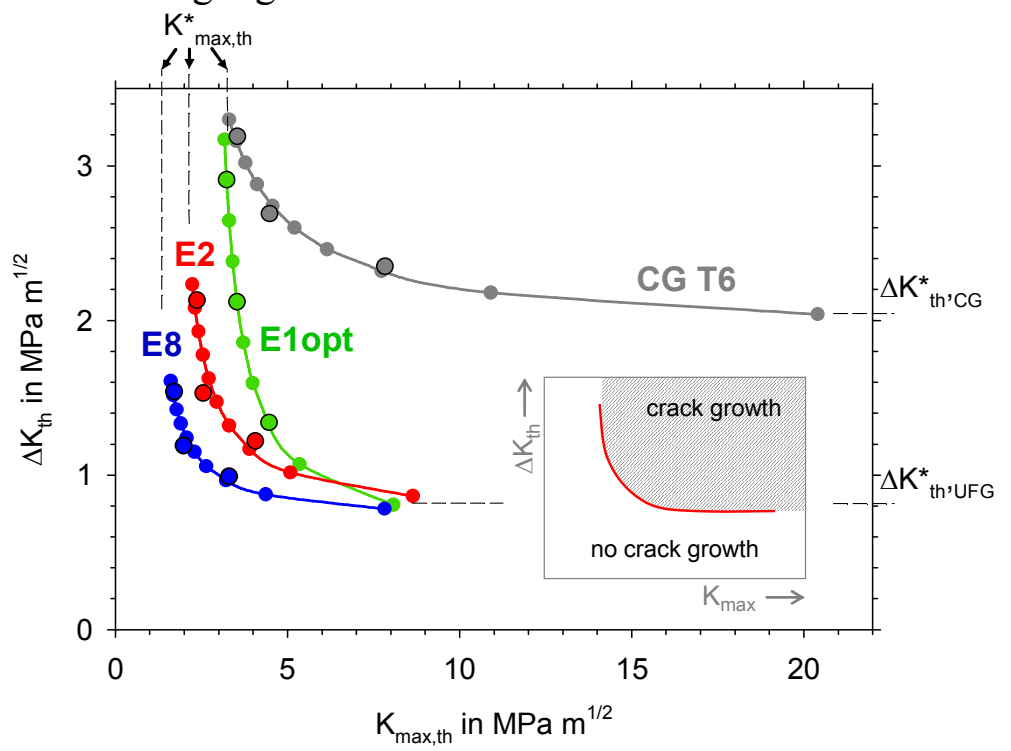

Fig. 6: Plot of $\Delta \mathrm{K}_{\mathrm{th}}$ and corresponding $\mathrm{K}_{\mathrm{max} \text {,th }}$ for load ratios from 0 to 0.9 (increasing $\mathrm{R}$ from left to right). Dots on line show data derived from the Barsom fit, three separate dots for each condition represent experimental values. The schematic in-set in the lower right corner originates from [8]. 
Plotting $\Delta \mathrm{K}_{\text {th }}$ and $\mathrm{K}_{\text {max,th }}$ as shown in Fig. 6 results in rounded, L-shaped curves for all conditions under investigation. This appearance is typical for rather ductile materials, which are grouped in a "class II behaviour" according to [9], where a pronounced curvature corresponds to a strong interaction of both critical parameters, as discussed above. $\Delta \mathrm{K}^{*}{ }_{\text {th }}$ and $\mathrm{K}^{*}{ }_{\text {max,th }}$ are determined by projection of the horizontal and vertical lines which are limiting the curvature. In the case of $\Delta \mathrm{K}^{*}$ th, the UFG conditions group together to one value of $\Delta \mathrm{K}^{*}{ }_{\text {th,UFG }}$ which is approximately one third of the critical value for the conventionally grained condition $\Delta \mathrm{K}^{*}{ }_{\text {th,CG. }}$ In the case of $\mathrm{K}^{*}{ }_{\text {max,th }}, \mathrm{E} 8, \mathrm{E} 2$ and CG T6 show individual critical values, implying an effect of either strength or grain size (or both) on this parameter. This finding is consistent with literature data, where an increase in strength was found to decrease $\mathrm{K}^{*}{ }_{\text {max,th }}$ [9], and an increase in grain size led to higher $\mathrm{K}^{*}{ }_{\text {max,th }}$ [21]. However, E1opt deviates from this trend, which prevents us from assuming an over-simplified relation. Most likely, the effect of precipitates and slip character - as discussed above - has to be considered in greater detail in order to fully relate the behaviour of Elopt in terms of $\mathrm{K}^{*}$ max,th. This will be dealt with in further studies.

\section{Summary}

In this study, the load ratio dependent threshold of fatigue crack propagation was investigated for an aluminium alloy processed by ECAP. The results imply a strong dependency of the threshold as well as its load ratio sensitivity on the grain size and grain size distribution. Further influence was observed in the altered precipitation characteristics of the ductility-optimized condition. Evaluating the threshold data $\Delta \mathrm{K}_{\mathrm{th}}$ using the two-parametric concept of Vasudevan and Sadananda, all investigated conditions fall into class II behaviour. In terms of $\Delta \mathrm{K}^{*}$ th, the first critical parameter, a general classification into "UFG" and "CG" can be observed. The second critical parameter, $\mathrm{K}^{*}$ max,th, takes on individual values for all conditions under investigation and is therefore shown to depend on strength and/or grain size. As an exception from this trend, the ductility-optimized condition reveals a superior $\mathrm{K}^{*}{ }_{\text {max,th}}$, which deviates from the simple "grain size $-K^{*}{ }_{\text {max }, t h}$ " trend. This implies that the applied combination of ECAP and aging effectively enhances the FCP behaviour of the UFG aluminium alloy.

\section{Acknowledgements}

The authors gratefully acknowledge the financial support of the German Research Foundation (DFG) within the framework of SFB 692.

\section{References}

[1] A. Vinogradov: J. Mater. Sci. 42 (2007), p.1797.

[2] Y. Estrin and A. Vinogradov: Int. J. Fatigue 32 (2010), p. 898.

[3] H.W. Höppel: Mater. Sci. Forum Vol. 503-504 (2006), p. 259.

[4] H.J. Maier, P. Gabor, N. Gupta, I. Karaman and M. Haouaoui: Int. J. Fatigue 28 (2006), p. 243.

[5] L.W. Meyer, K. Sommer, T. Halle and M. Hockauf: Mater. Sci. Forum Vol. 584-586 (2008), p. 815.

[6] P.S. Pao, H.N. Jones, S.F. Cheng and C.R. Feng: Int. J. Fatigue 27 (2005), p.1164.

[7] P. Hübner, R. Kiessling, H. Biermann, T. Hinkel, W. Jungnickel, R. Kawalla, H.W. Höppel and J. May: Metall. Mater. Trans. A 38 (2007), p. 1926.

[8] A.K. Vasudevan, K. Sadananda and N. Louat: Scr. Metall. Mater. 28 (1993), p. 65.

[9] A.K. Vasudevan and K. Sadananda: Metall. Mater. Trans. A 26 (1995), p. 1221.

[10] S.E. Stanzl-Tschegg, O. Plasser, E.K. Tschegg and A.K. Vasudevan: Int. J. Fatigue 21 (1999), p. 255.

[11] M.D. Chapetti, H. Miyata, T. Tagawa, T. Miyata and M. Fujioka: Int. J. Fatigue 27 (2005), p. 235.

[12] J.M. Barsom: Weld. Res. Council Bull. 194 (1974), p.1.

[13] R. E. Barber, T. Dudo, P.B. Yasskin and K.T. Hartwig: Scr. Mater. 51 (2004), p. 373.

[14] Standard Test Method for Plane-Strain Fracture Toughness of Metallic Materials, ASTM E399-90, ASTM, Philadelphia, PA, 1997

[15] M. Hockauf, L.W. Meyer, T. Halle, C. Kuprin, M. Hietschold, S. Schulze and L. Krüger: Int. J. Mater. Res. 97 (2006), p. 1392.

[16] M. Hockauf, L.W. Meyer, B. Zillmann, M. Hietschold, S. Schulze and L. Krüger:Mater.Sci.Eng.,A 503(2009),p.167.

[17] E. Hornbogen and K.-H. Zum Gahr: Acta Metall. 24 (1976), p. 581.

[18] R. Carter, E. Lee, E. Starke and C. Beevers: Metall. Mater. Trans. A 15 (1984), p. 555.

[19] H.J. Roven, M. Liu and J.C. Werenskiold: Mater. Sci. Eng., A 483-484 (2008), p. 54.

[20] M. Cai, D.P. Field and G.W. Lorimer: Mater. Sci. Eng., A 373 (2004), p. 65.

[21] A.K. Vasudevan, K. Sadananda and K. Rajan: Int. J. Fatigue 19 (1997), p. 151. 